\title{
Using case studies to promote life-long learning
}

\author{
Robert M. Aiken, Cheryl Sandas, \\ Ned Kock and Munir Mandviwalla \\ Computer and Information Sciences Department, Temple University \\ Management Information Systems Department, Temple University
}

\begin{abstract}
This paper examines issues associated with developing and teaching a course in computer fluency for non-computer and information science (CIS) majors. One of the key objectives of the course is to motivate students on the importance of keeping abreast of developments in information technology (IT) far beyond the duration of the course. Feeling comfortable with using IT is a 'sine qua non' for a society becoming increasingly technologically dependent. Among the issues investigated is the role of teaching a programming language, possible pre-requisites, the background needed to teach such a course, and the key components on which the course might be based. Observations are based on developing and teaching this course, plus providing a workshop to colleagues in the College of Education. Among our observations: case studies work but they need to be more central to students' majors, and if a programming language is not taught it is not necessary that a CIS faculty member teaches the course. Also, a capstone project is needed, hands-on laboratory exercises are a key (particularly in terms of collaborative work), team teaching works, while integrating different viewpoints and skill sets is difficult but rewarding. The workshop provided us with comments from colleagues about our approach to developing a fluency in an information technology course.
\end{abstract}

Key words: life-long learning, case studies, computer fluency, team teaching

The original version of this chapter was revised: The copyright line was incorrect. This has been corrected. The Erratum to this chapter is available at DOI: 10.1007/978-0-387-35615-0_52 


\section{INTRODUCTION}

Information technology (IT) is central to modern (ISTE, 1998). Learning to use IT effectively in individual and organisational domain-specific processes cannot be done in a single step. Such learning requires appropriate introductory concepts, experiences, and motivations, and a life-long commitment to learning.

Courses that introduce IT generally fall into one of the following categories: 'computer literacy', 'programming', 'great ideas of computer science', and 'computer and society'. Such courses seldom combine the following elements: understanding of IT ideas and instruments, understanding of IT's role in framing and solving specific problems in various disciplines, and the ability to actually use IT to solve these problems. Students who are interested in specific themes and subject domains (such as chemistry, sociology, or anthropology) need to understand IT from the perspective of these domains.

The question we address is how to bring students to the level beyond the introductory course. At this new level students should be able to integrate IT into the problem-solving logic and operation of their specific disciplines. We have developed a new course to achieve this transformation. It demonstrates through complex case studies the power of IT integration. We incorporate in-depth case studies as the best approximation to apprenticeship learning. In brief, the goals are to provide students with the background and motivation to both feel comfortable with using technology as well as provide the 'raison d'etre' for them to want to stay up-to-date with technological development. An early perspective on teaching this course can be found in Aiken, Kock et al. (2000).

We should note here that the planning for this project has been underway for several years and was independent of the 'Being Fluent with Information Technology' report that was written by a Committee on Information Technology Literacy and published by the National Academy Press (1999). However, in many ways our ideas and concerns are similar. What we discuss is one specific way to address the concerns in this report of how to make a larger number of college/university students fluent in technology and life-long users of IT.

Principal objectives of our approach include establishing a framework to develop portable case studies, assessing the effectiveness of the course in achieving its stated goals, and disseminating our results as widely as possible. This is certainly consistent with the above-mentioned report which states, "In summary, FIT individuals, those who know a starter set of IT skills, who understand the basic concepts on which IT is founded, and who have engaged in the higher-level thinking embodied in the intellectual 
capabilities, should use information technology confidently, should come to work ready to learn new business systems quickly and use them effectively, should be able to apply IT to personally relevant problems, and should be able to adapt to the inevitable change as IT evolves over their lifetime" (Committee on Information Technology Literacy, 1999).

\section{PEDAGOGICAL OBJECTIVES}

In designing this course we decided to proceed from a set of pedagogical objectives that are consistent with standards in general use (ISTE, 1998). The following six objectives were chosen to provide the backbone for the course:

a) Basic operations and concepts

Students will demonstrate a sound understanding of the nature and operation of technology. Examples of these are: understanding the concepts of files and error recovery, and the ability to apply and adapt IT tools to solve problems in new situations.

b) Social, ethical, and human issues

Students will understand the ethical, cultural, and societal issues related to technology. Students will practice responsible use of information systems and software. Students will develop positive attitudes toward technology uses that support life-long learning, collaboration, personal pursuits, and productivity. These objectives are covered in lectures, and include topics such as applying IT unnecessarily and the ability to discern appropriate/inappropriate uses of IT.

c) IT as a productivity tool

Students will use IT to enhance learning, increase productivity, and promote creativity. Students will use IT to collaborate in constructing technology-enhanced models, in preparing publications, and in producing other creative works. Examples of these are: tutoring systems, web authoring tools, geographic information systems and Microsoft Office.

\section{d) Expressive and collaborative communication}

Students will use IT to collaborate, and interact with peers and other audiences. Students will use a variety of media and formats to communicate information and ideas effectively to multiple audiences. Some examples of this are: a bulletin board for the group project, email and the final project.

\section{e) IT as a research tool}

Students will evaluate and select new information resources and technological innovations based on the appropriateness to specific tasks. Some examples include: using search engines to locate relevant information to solve problems and posing questions related to their or other disciplines 
and using IT to collect, organise, and represent data to answer those questions.

\section{f) IT problem-solving and decision-making tools}

Students will use IT for solving problems and for making informed decisions. Students will employ technology in the development of strategies for solving problems in the real world. Some examples include: having students select and use appropriate IT tools for a task, showing how IT is used to conduct scientific research by people in various fields, and applying IT to complex problems.

The major components of the course are case study lectures and labs, information technology lectures and labs, a weekly journal, and a final project. Although the foundation for achieving the aforementioned objectives is laid down in the lectures and labs, the objectives are operationalised in the journals and the final project.

Journals allow the students to reflect on individual sections of the course as well as the course as a whole. By mandating journals, we gain insight into the cognitive processes of the students that we may not gain otherwise. For example one student remarked: "The application of this type [of] procedure will definitely be useful when interacting with almost any type of software or even with products that are not directly related to computers" [sic]. The requirement to generate a written record encourages students to reflect and connect the concepts presented. Students can discover how the IT with which they are interacting can be used within their own discipline/personal life in addition to how IT is used within the discipline of the case study presenter. For example one student noted that "Shift-share analysis and spread sheets can probably be used in almost any discipline in which large amounts of data have to organised and analyzed" [sic]. The demonstrated objectives are: social, ethical and human issues; use of a technology research tool; and use of technology and decision-making tools.

The final project provides students with an opportunity to demonstrate their knowledge of IT and to synthesise the concepts covered throughout the course. Students can develop their own final project or choose from among the ones provided. All projects must be available via an organised web site. In addition, students must supply two progress reports during the semester and present their project web-site to the class.

For example, one student chose to create a web-site for a psychic business. This student used MS FrontPage to create his site, MS Excel to create the spreadsheets in his business plan, and MS Word to compose the written content of the business plan. In addition, he used the web to research psychic sites for content and prices to forecast his sales. He also used the web to assess the competition for this type of business. The end result was a working psychic web-site and links to the mission statement, business plan, 
and contact information. By having this framework for the final projects, students cover the following objectives: basic operations and concepts, technology productivity tools, expressive and collaborative communication, technology research tool, and technology problem-solving and decisionmaking tools.

Experience in teaching this course shows that there are pedagogical and administrative challenges. However, the course is rewarding and provides students with a unique perspective on the uses of IT. More detailed information can be found in Aiken and Sandas (2001) and Kock, Aiken et al. (forthcoming). This course provides schools with a solution of how to go beyond a typical computer literacy course for non-computer science and MIS majors. A key practical consideration is how to staff the course. This is especially important since most computer and information science departments do not have sufficient resources to even teach all the courses for their own students.

One possible solution, which we propose here, is to leave programming out of the course and design the content so that someone who is not a computer scientist, but who is knowledgeable about computing, and who uses IT in their research and teaching, can teach the course. In order to follow-up on this observation we are encouraging colleagues in other disciplines to develop and teach a similar course in their own field. To this end, we have offered a half-day workshop to colleagues from Temple University's College of Education that presents our approach. In addition to sharing our approach, we were able to get feedback from the participants, which is summarised in the next sections.

\section{WORKSHOP ISSUES}

One of the key issues with which we have struggled is how we can make this course accessible to as many students as possible. In our view we needed to design the course in such a way that colleagues from areas other than computer science, management information systems (or related disciplines) could teach the course. Taking one step in this direction, we organised a workshop for fifteen computer literate colleagues in our college of education in order to share our thoughts and learn from their feedback. These colleagues were invited, based on their previous track record of integrating IT into their courses. The goal was to encourage these participants to consider developing a course similar to ours for students in their college. The authors worked with a colleague in the college to identify possible attendees and to design the workshop in such a way as to attract the most interest. 
The workshop was organised around two panel discussions and followup questions. It included informal, interactive discussions on two main issues: 'Incorporating IT into Education: What are the Issues?' and 'Potential Approaches to Life-long Learning of IT in Education'. With regards to the first issue we explored questions such as 'How do you know what is available and how to use it?', 'How can we get beyond basic skills and use technology resources to enhance learning?'.

With respect to the second issue we examined questions such as, 'What approaches are available to help us 'be fluent' in using information technology resources in support of learning and instruction?' and 'What approaches should be available?'. In brief we asked panellists and participants to share their experiences, thoughts and concerns about how people move from basic computer skills to the point of being able to use IT resources 'fluently' in the work of their profession. Some of the points that emerged from these discussions were surprising to us. We have summarised the highlights of the second issue in the next section.

\section{WORKSHOP POINTS REGARDING OUR COURSE FOR LIFE-LONG LEARNERS}

1. A case study approach fits well with the team teaching that is currently being utilised in some college of education classes.

2. An IT fluency class would be beneficial to graduate as well as undergraduate students.

3. A fluency course would be an advisable and natural follow-up to the current computer literacy course required by the College of Education.

4. The College of Education faculty needs to be exposed to IT concepts to facilitate their becoming life-long learners.

5. The challenge of presenting a unifying theme across the case studies could be overcome by having all of them relate to education or the home department of the course.

6. The students should be evaluated on their work not on their domain knowledge if the case studies are from other disciplines.

7. Student journals can be used to gain insight into what the students are learning and to obtain informal feedback on the course content.

8. The final project should demonstrate to what extent the students have synthesised the material presented throughout the semester.

9. The absence of programming was seen as a positive aspect of the course. 


\section{CONCLUSIONS}

In general, the course has met our most important objectives - those of providing the students with sophisticated computing skills and the knowledge that it will be necessary for them to continually hone these skills, as well as an understanding of how complex IT can be used in specific domains. As each generation becomes more computing proficient than the generation that preceded it, the need for such courses will decrease. But for the current generation of college students a course such as this is a necessity, not a luxury. In order to provide a course that best fits the needs of the largest number of students, this course offers a model on which a non-CIS faculty can build. Our experience in discussing the format and principles of the course with colleagues in Temple University's College of Education was very positive. We plan to offer additional workshops to colleagues in other disciplines (and possibly other colleges) based on the results of these discussions. The results of the workshop suggest that a second level IT course can be best taught in the context of specific disciplines at specific academic units, for example, colleges of education, schools of business, natural sciences divisions, etc. This would more easily allow instructors to 'team teach' the course, avoid staffing problems, and provide examples more aligned with the students' backgrounds and interests. Readers are encouraged to visit our web site http://ww2.cis.temple.edu/nsflll for additional information on these and other aspects of the course.

\section{REFERENCES}

Aiken, R., Kock, N. and Mandviwalla, M. (2000) Fluency in Information Technology: A Second Course for non-CIS Majors. Proceedings of SIGCSE 2000. New York: ACM

Aiken, R. M. and Sandas C. (forthcoming) A Life-long Learning Course Based on Learning Objectives. Proceedings of World Conference on Computers and Education (WCCE 2001), Copenhagen, July 2001.

Committee on Information Technology Literacy (1999) Being Fluent with Information Technology. Washington, D.C.: National Academy Press

International Society for Technology in Education (ISTE) (1998). ISTE Guidelines - NETS Project, 'National Educational Technology Standards for Students'.

Kock, N., Aiken, R. and Sandas, C. (forthcoming) Using Complex IT in Specific Domains: Developing and Assessing a Course for Non-Majors. IEEE Transactions on Education

Toffler, A. and Toffler, H. (1995) Creating a New Civilization: The Politics of the Third Wave. New York, NY: Turner Publications 


\section{BIOGRAPHIES}

Robert Aiken is a professor in the Computer and Information Sciences Department, Temple University. He is the (co-)author of three books as well as more than 80 articles in refereed journals and proceedings. His current research includes developing and testing the effectiveness of intelligent collaborative learning systems on e-learning, and assessing the impact of technology in K-12 education. Cheryl Sandas received her M.S. in computer and information sciences from Temple University. Munir Mandviwalla, associate professor, is founding chair of the Management Information Systems in the Fox School of Business and Management at Temple University, and Executive Director of the Irwin L. Gross eBusiness Institute. Ned Kock is director of the E-Collaboration Research Center and CIGNA research fellow in the Fox School of Business and Management, Temple University, Philadelphia. He is the author/co-author of three books and numerous articles published in journals including Communications of the ACM, IEEE Transactions on Education, and IEEE Transactions on Professional Communication.

\section{ACKNOWLEDGEMENTS}

The authors would like to thank Professors D. Dalton, D. Elesh and A. Ranere for both their design of the case studies, and their teaching of them. Also, we would like to thank Professor Glenn Snelbecker and Mr. Terry McLonogue from Temple University's College of Education for their support in assisting with the selection of participants for the workshop.

${ }^{1}$ The development of this course is in poart funded by a grant from the National Science Foundation, DUE 9951418. 